\title{
A produção de teses e dissertações sobre centros culturais
}

\author{
The thesis and dissertation production on cultural centers
}

\section{La produccion de estudios acerca de centros culturales}

\author{
Mario Fernandes da Silva ${ }^{1}$ \\ Luiz Octávio de Lima Camargo ${ }^{2}$ \\ Marielys Siqueira Bueno ${ }^{3}$
}

\begin{abstract}
Resumo: Na intersecção das noções de cultura e turismo, os centros culturais cada vez mais se destacam nas grandes e médias cidades, constituindo referência geográfica e de prestígio para seus moradores atrativo para turistas. Este artigo tem como objetivo central analisar a produção bibliográfica sobre os centros culturais e, como específicos, discutir e criticar a noção de cultura embutida na sua ação bem como sistematizar a produção sobre o tema, destacando a interface entre os conceitos e práticas de cultura e turismo. A metodologia utilizada foi a descritivo-interpretativa. A base de dados utilizada foi o Banco de Dissertações e Teses da CAPES, de 1987 a 2010, nas quais se encontra a expressão exata centro cultural no título e/ou palavra chave e/ou resumo, resultando em 116 teses/dissertações. Os referenciais teóricos são autores das áreas de cultura e turismo. Os resultados mostram que a produção acadêmica está em crescimento tanto nos programas de universidades públicas como privadas, mas que, em geral, optam por abordagens que não questionam os conceitos de cultura utilizados e embutidos no planejamento e na ação desses centros. Destaque-se igualmente o pequeno interesse sobre o tema nos estudos turísticos, para os quais os centros culturais são considerados apenas como oferta dentro do turismo cultural, esquecendo a sua dimensão educativa.
\end{abstract}

Palavras-chave: Cultura. Centro cultural. Ação cultural. Turismo.

Abstract: At the intersection of the notions of culture and tourism, cultural centers increasingly stand out in large and medium cities, making geographic reference and prestige for locals and tourists. This article aims at examining the production of literature on cultural centers and as specific, discuss and criticize the notion of culture embedded in their action and systematize the production on the topic, highlighting the interface between the concepts and practices of culture and tourism. The methodology used was descriptive and interpretive.. The database used was the Bank Theses CAPES, 1987-2010, in which is the exact expression cultural center in the title and / or keyword and / or short, resulting in 116 theses / dissertations.

\footnotetext{
${ }^{1}$ Universidade Anhembi Morumbi. Serviço Social do Comércio de São Paulo (SESC). E-mail: mfsprof@ig.com.br

${ }^{2}$ Universidade Anhembi Morumbi / Universidade de São Paulo. E-mail: octacam@uol.com.br

3 Possui graduação e Licenciatura em Pedagogia pela Faculdade de Filosofia Bernardo Sayão (1969), mestrado em Antropologia pela Universidade Federal de Goiás (1976) e doutorado em Sociologia pela Universidade de São Paulo (1988). Diplôme de Études approfondies en Anthropologie sociale. Université René Descartes - Paris V. Diplôme de Études Approfondies en Cinéma Anthropologiques. Unversité Nanterre - Paris X. Atualmente é professor da Universidade Anhembi Morumbi. Tem experiência na área de Antropologia, atua principalmente nos seguintes temas: hospitalidade, dádiva, festa, comensalidade e turismo. E-mail: marielysbueno@gmail.com
} 
Theoretical frameworks are authors of the areas of culture and tourism. The results show that production is growing academic programs in both public and private universities, but that in general, choose to approaches that do not question the concepts of culture used and embedded in the planning and action of these centers. Register equally the little interest in the topic in tourism studies, for which the cultural centers are considered only within the cultural tourism offer, forgetting their educational dimension.

Keywords: Culture. Cultural center. Cultural action. Tourism.

Resumen: En la intersección de las nociones de cultura y turismo, centros culturales se destacan cada vez más en las grandes y medianas ciudades, siendo referencia geográfica y de prestigio para los lugareños y turistas. Este artículo tiene como objetivo analizar la producción de literatura sobre centros culturales y de lo más específico, discutir y criticar la noción de cultura integrada en su acción y sistematizar la producción sobre el tema, destacando la interrelación entre los conceptos y prácticas de la cultura y el turismo. La base de datos utilizada fue la CAPES Banco tesis, 1987-2010, en la que es la expresión cultural en el centro exacto del título y/o una palabra clave y/o resumen, lo que resultó en 116 tesis / disertaciones. Marcos teóricos son autores de los ámbitos de la cultura y el turismo. Los resultados muestran que la producción está creciendo em los programas académicos en las universidades públicas y privadas, pero que, en general, optan por enfoques que no cuestionan los conceptos de cultura utilizados e incluidos en la planificación y las actividades de estos centros. Regístrese igualmente poco interés en el tema en los estudios de turismo, para lo cual los centros culturales se consideran sólo dentro de la oferta de turismo cultural, olvidando su dimensión educativa.

Palabras clave: Cultura. Centro Cultural. Acción cultural. Turismo.

\section{INTRODUÇÃO}

Os centros culturais, na esteira do prestígio do Centre Beaubourg, em Paris, do Guggenheim em Nova lorque (EUA) e em Bilbao (Espanha), do SESC-Pompéia em São Paulo, apenas para citar alguns exemplos, hoje constituem referências turísticas das cidades, embelezam cartões postais e são incluídos na pauta de atrativos, tanto para moradores como para turistas. Ademais, constituem uma das primeiras alternativas pensadas para a reciclagem do patrimônio e, assim, antigas edificações que perderam sua finalidade original, mas merecem ser preservadas são pensadas para uma nova função, a de centros culturais, centros de cultura, casas de cultura, etc... A implantação de centros culturais constitui também uma das principais rubricas dos planos de governo municipais e estaduais.

Com isso, pode-se dizer que uma das perspectivas da abordagem desse objeto mergulha na intersecção dos temas cultura, turismo, patrimônio e políticas públicas. Diante dessas considerações, é de se perguntar: qual a situação dos estudos referentes a centros culturais no Brasil e sua interface com o turismo?

O objetivo central desta comunicação é, pois, apresentar os resultados obtidos a partir da análise da produção das teses e dissertações que se vincularam ao tema dos Centros Culturais. Adicionalmente, visa entender como e de que forma os centros culturais constituem pauta de pesquisa nos estudos turísticos. 
Este artigo seguirá, assim, o seguinte arrazoado: após a descrição dos referenciais metodológicos, segue-se um resumo do referencial teórico utilizado, dos resultados obtidos e das considerações finais.

\section{MATERIAL E MÉTODOS}

Optou-se neste artigo pela utilização de análise da produção bibliográfica sobre "centro cultural" ao invés de Estado da Arte sobre "centro cultural" utilizando como material de estudo não a totalidade do conhecimento existente nos diferentes tipos de estudo, mas tão somente as dissertações e teses. Se estas apenas desvelam parte da produção, trazem, em contrapartida os horizontes do tema e para onde caminham as pesquisas. Afinal, as dissertações e teses constituem as fronteiras da pesquisa científica, que dão origem ao surgimento de novos autores e de novos temas.

Posteriormente, os estudos foram analisados sob duas óticas. A primeira, de caráter quantitativo, busca apresentar o cenário geral, no qual os estudos analisados se encontram, identificando-se a cronologia dos estudos, o estado acadêmico, o caráter das instituições, o financiamento das pesquisas e a prevalência do aparecimento da expressão "centro cultural".

A segunda ótica está na perspectiva qualitativa dos estudos, no chamado método descritivo-interpretativo. É descritivo na medida em que relaciona as diferentes unidades de análise e interpretativo

no sentido de ampliar a compreensão dos fenômenos investigados, num esforço em expressar intuições e novos entendimentos atingidos implicando construir relações entre as unidades de base, combinando-as e classificando-as no sentido de compreender como esses elementos unitários podem ser reunidos na formação de conjuntos mais complexos, as categorias (Moraes, 2003, p. 191).

A análise e discussão dos resultados, a partir de categorias identificadas nos conteúdos dos estudos, deve apontar aspectos aglutinadores na intersecção dessas categorias com as áreas do conhecimento. Ferreira propõe dois momentos na pesquisa: primeiro levanta-se a produção acadêmica, através da qual o pesquisador quantifica e identifica o material colhido; num segundo momento, deve-se traçar "tendências, ênfase, escolhas metodológicas e teóricas, aproximando ou diferenciando trabalhos entre si, na escrita de uma história de uma determinada área do conhecimento" (Ferreira, 2002, p.265). Aqui, ele deve buscar responder além das perguntas quando, onde e quem produz pesquisas num determinado período e lugar, aquelas questões que se referem a 'o quê' e o 'como' dos trabalhos.

A investigação empírica mais detalhada obedeceu aos seguintes passos:

a) levantamento realizado no dia 05 de setembro de 2011, englobando dissertações e teses desde 1987 até 2010 , nas quais se encontra a expressão exata "centro cultural" no título e/ou palavra chave e/ou resumo.

b) a partir dos estudos apurados, procedeu-se à leitura crítica de todos os resumos dos estudos apurados sobre o tema; 
c) esses estudos foram discriminados segundo sua cronologia, áreas de pesquisa, tipos de instituições, vinculações a agências de fomento;

d) análise dos estudos dentro das categorias ação cultural, planejamento da ação cultural, planejamento de centros culturais.

\section{A POLISSEMIA DA NOÇÃO DE CULTURA}

Segundo Teixeira Coelho (1986), no século XIX foram criados os primeiros centros de cultura ingleses, chamados de centros de arte. Estes espaços já assumiam a prática da ação sociocultural que foi privilegiada pelas políticas culturais dos países socialistas europeus no século XX. Mas, somente no final da década de 50, na França, foram lançadas as bases do que contemporaneamente entende-se como ação cultural e equipamento cultural.

entendendo-os como edificações destinadas a práticas culturais (teatros, cinemas, bibliotecas, centros de cultura, filmotecas, museus), quanto grupo de produtores culturais abrigados ou não, fisicamente, numa edificação ou instituição (orquestras sinfônicas, corais, corpos de baile, companhias estáveis, etc.). (Coelho, 1997, p165).

Qual a noção de cultura sobre a qual estes equipamentos são planejados e implantados? Resumindo, há que se distinguir, com Jaeger $(1989$, p.6), a cultura nos seus sentidos formativo e descritivo. Esta última é a que orienta os estudos antropológicos, englobando todas as formas de subsistência e de existência de uma dada população. Já a cultura no sentido formativo descende em linha reta da Paidéia da Grécia clássica. Logo o sentido formativo da palavra cultura se depara com o impulso criador do povo, ou seja, da humanidade hoje, como se entende o mundo, como se percebem uns aos outros, porque se faz isso ou aquilo, porque se aprecia o belo, enfim está ligado com a forma de vida que palpita nos dias de hoje.

Segundo Jaeger, "foi sob a forma de Paidéia", de cultura, que os Gregos consideraram a totalidade da sua obra criadora em relação aos outros povos da antiguidade de que foram herdeiros" (1989, p 06).

Sobre a noção antropológica descritiva, a hoje mais habitual das noções, entende-se a cultura não no sentido de um ideal, mas numa acepção mais ampla que se estende a todos os povos, inclusive os primitivos. Segundo Jaeger (1989).

hoje estamos habituados a usar a palavra cultura não no sentido de um ideal próprio da humanidade herdeira da Grécia, mas antes numa acepção bem mais comum, que se estende a todos os povos da Terra, incluindo os primitivos. Entendemos assim por cultura a totalidade das manifestações e formas de vida que caracterizam um povo. (Jaeger, 1989, p.06)

4 Segundo Platão "(...) a essência de toda a verdadeira educação ou Paideia é a que dá ao homem o desejo e a ânsia de se tornar um cidadão perfeito e o ensina a mandar e a obedecer, tendo a justiça como fundamento" (apud Jaeger, 1989, p. 147) 
Sobre o sentido formativo da noção de cultura, vale a distinção histórica entre o mundo pré-helênico e o mundo que se inicia com os Gregos. A partir disso, afirma-se que os gregos foram os criadores da ideia de cultura, que se origina na noção de Paidéia, não como um aspecto exterior à vida, deslocado do sujeito. Ao contrário, a palavra cultura se depara com o impulso criador do povo, ou seja, da humanidade hoje, como se entende o mundo, como se percebem uns aos outros, porque se faz isso ou aquilo, como se aprecia o belo. Enfim, esse sentido está ligado à forma de vida que palpita nos dias de hoje. Sobre o principio formativo Jaeger (1989) argumenta:

Quanto maior é o perigo de até o mais elevado bem se degradar no uso diário, com tanto maior vigor sobressai o profundo valor das forças conscientes do espírito que se destacaram na obscuridade do coração humano e estruturam, no frescor matinal e com o gênio criador dos povos jovens, as mais altas formas de cultura. (Jaeger, 1989, p. 7).

Percebe-se então que há claramente um apontamento para algo que não é dito, mas que está e estará presente na estrutura da sociedade contemporânea, que foi forjada desde a civilização grega.

Para Cunha (2010), o conceito de cultura ligado às ciências sociais remete aos estudos de Pierre Bourdieu (2007). Nesta visão, a noção de cultura explica-se a partir da interlocução de estrutura, habitus e práticas.

O primeiro diz respeito àquelas regularidades que são associadas a instituições e ambientes sociais (modos de produção e consumo de bens materiais ou abstratos, relações familiares, etc.). Tais estruturas produzem habitus, que é uma maneira de ser, um sistema de disposições duráveis capazes de funcionar como estruturas estruturantes, quer dizer como princípios de geração e de estruturação de práticas, e que ao longo do tempo acaba por funcionar, inconscientemente, como um princípio ao mesmo tempo arbitrário e interiorizado. As práticas, finalmente, são o resultado dialético entre uma estrutura e um habitus perante uma situação real ou concreta. (Cunha, 2010, p. 17)

Uma segunda acepção do termo apresentado por Cunha (2010) trata da ação de cuidar cultivar, não mais a terra, mas o espírito, o intelecto, os conhecimentos. Neste caso, o conceito de cultura está relacionado com a verdade de um conhecimento, com o bem de uma ação moral e com a beleza de uma representação artística. Complementar a essa ideia, o mesmo autor sugere ainda que o mundo da cultura seria o da contemplação, o da sabedoria, da memória, do bem, da verdade e do belo, seria, portanto um ideal.

Segundo Cunha (2010), há um possível paralelo entre cultura e civilização dentro do chamado processo civilizador, na forma concebida por Norbert Elias (1990), que associa os conceitos de civilização, urbanidade, polidez, educação de hábitos sociais e aprimoramento da sensibilidade.

Outro sentido para a palavra cultura seria aquele ligado às manifestações que têm origem na língua, com suas variações dadas pelos comportamentos sociais ou hábitos do cotidiano, ficando mais evidentes nas criações artísticas ou artesanais populares. Portanto, sob certo ponto de vista, conclui o autor que cultura é aquilo que se atribui uma espécie de essência espiritual, que distingue e provoca um sentimento de pertencimento étnico ou nacional, isso recentemente daria origem à reivindicação atual pelos direitos culturais de um determinado povo. (Cunha, 2010) 
Os centros culturais naturalmente são herdeiros dessa polissemia dos conceitos de cultura e de ação cultural. Podem partir de uma noção socioeducativa e assim privilegiar todas as manifestações culturais da população a que serve. Mas podem ser também segregadores quando se imaginam os únicos representantes da "alta cultura", excluindo dimensões importantes da cultura contemporânea, atividades menores como o lazer, o turismo, o esporte e a atividade física em geral.

Esta dicotomia da noção descritiva e formativa da cultura também é abordada por Santos (1996). Para o autor, o termo pode estar associado a estudo, educação, formação escolar, tendo portanto um sentido formativo. Pode também incorporar as manifestações artísticas, tradicionais de um povo, suas festas, cerimônias, lendas e suas crenças. O autor finaliza ampliando seus sentidos, posicionando-se no significado de cultura "de maneira mais genérica, preocupado com tudo o que caracteriza uma população humana" (Santos, 1996, p.22). O mesmo autor ainda indica que "o que importa é que pensemos sobre os motivos de tanta variação, que localizemos as ideias e temas principais sobre os quais se sustentam" (Santos, 1996, p.22).

No que diz respeito à noção de cultura, desde a década de 1950, edifícios consagrados às práticas culturais, sobretudo artísticas, e, por isso mesmo, designados centros culturais, vêm se tornando item essencial no planejamento urbanístico turístico e uma grife na competição de prestígio entre as cidades. Donde sua vinculação às políticas públicas de turismo.

Especificamente sobre o planejamento do centro cultural, não se podem negligenciar os atributos dos agentes culturais responsáveis por estes centros. Segundo Teixeira Coelho (1986), os agentes culturais precisam dominar mecanismos para despertar nas pessoas um movimento para a ação criativa em grupo, conhecer o contexto local quando se intervém culturalmente em uma determinada coletividade e conhecer minimamente os códigos e pressupostos teóricos relacionados à determinada prática artística.

Além desses três pontos, soma-se um quarto, que diz especificamente ao planejamento do centro cultural, seria a capacidade de administrá-lo. Neste sentido, apresentam-se os requisitos fundamentais para que os responsáveis pelo centro cultural possam realizar uma política direcionada ao fortalecimento da cultura como práxis. No processo de trabalho que se estabelece dentro de um centro cultural, o agente cultural é um fomentador, alguém que faz as mediações, por isso deve estar atento aos códigos artísticos, pois deve ter domínio do que está em jogo quando se trabalha com a cultura. (Teixeira Coelho, 1986)

Sobre as condições de atuação de um centro cultural, Teixeira Coelho (1986) afirma que, sejam quais forem essas condições, o centro cultural deve ser local de inovação, de descoberta, de desvelamento da realidade. Para o autor, um centro cultural deve optar pelo indivíduo numa situação coletiva, pois este centro só tem razão de existir se está comprometido com a formação de sujeitos e sua inserção num ambiente coletivo, pois somente a partir de indivíduos conscientes de sua existência na coletividade é possível a construção de cidadão crítico e ativo ciente de seu papel na sociedade. 


\section{CULTURA E TURISMO}

Não há dúvida de que este diálogo poderia ser ampliado à exaustão, porém não é o foco restrito deste artigo. Mas vale ressaltar a necessidade de se apontar qual seria a principal intersecção ou interesse dos centros culturais, quando se coloca em destaque a noção de cultura.

Neste sentido, surge uma discussão no âmbito de um mundo globalizado, que, por sua vez, caracteriza a cultura a partir de sua diversidade. Esse processo de natureza histórico-cultural torna as fronteiras tradicionais porosas, gerando novas práticas e relações entre as comunidades. Nesse contexto a cultura passa a ser um dos principais instrumentos de definição, particularização e mobilização das comunidades. Se por um lado globalização significa abertura, por outro, representa também uma ameaça potencial de uniformização e homogeneização, de imposição de modelos de consumo por parte dos centros de poder na configuração mundial. Esta força globalizante tem o turismo como uma das pontas de lança.

Essa universalidade alimentada vorazmente pelos meios de comunicação age na intenção da massificação de consumo dos bens culturais (Gonçalves, 2008). Na contramão deste processo as questões culturais assumem papel estratégico de resistência buscando a afirmação de identidades e de sentimentos de pertencimento de cada indivíduo, de cada comunidade, de cada nação. Sugere-se, portanto, que o maior desafio legado aos centros culturais seria representado pelo trinômio: integração/diversificação/sustentabilidade.

O enfrentamento deste desafio coloca, assim, o turismo no meio da questão. O estudioso do turismo pode considerar os centros culturais mais do que um item na descrição da oferta turística e indagar os fundamentos doutrinários de sua ação educativa. Em outras palavras, esta postura implica, sobretudo, na adoção de medidas que favoreçam o reconhecimento da peculiaridade de cada local. Implica ainda que reforcem os vínculos de pertencimento entre o indivíduo e seu grupo, entre o sujeito e o meio ambiente e a sociedade, atendendo às demandas contemporâneas sem deixar de proteger os recursos humanos, culturais e naturais, garantindo desta forma esse mesmo direito às gerações futuras (Durand, 2001). Esse enfrentamento pode representar a noção de cultura a ser trabalhada nos centros culturais, que por sua vez devem mobilizar suas ações no sentido de não permitir que o mundo se torne monocórdio, uma geleia amorfa sem gosto e sem cor.

Reforçando a reflexão, pode-se dizer que o turismo têm diferentes impactos nesse contexto. A "invenção" dos centros culturais caracteriza-se ora pela valorização da cultura local e de suas principais realizações ora pela sua homogeneização em relação aos exemplos mais famosos, tal como uma nova moda. Parafraseando estudos sobre a moda-vestuário, estes permitem uma observação paradoxal: quanto mais as cidades procuram ser originais, mais se tornam semelhantes. E, como em todas as modas, interessam mais pela visibilidade do que por uma busca de identidade. Ou, como diz Garcia e Bahl (2011, p.35) 
semelhança com as outras, sem demonstrar as suas imagens com seus valores históricos, e sem serem lembradas pelos seus próprios potenciais; o outro é o fato de o visitante interpretar como sendo um potencial artificial, sem significativos potenciais turísticos, e consequentemente, sem valores individuais da especificidade cultural, uma vez que elas se submetem aos julgamentos individuais.

Acrescente-se que, conforme Costa, as relações entre turismo e cultura são mais complexas do que parecem, já que "as organizações da área da cultura e patrimônio possuem pouca importância e influência na organização e gestão regional do sector (sic) do turismo (2005, p.290)". A preocupação é apenas com o hardware (o equipamento) e não com o software, nas vertentes imateriais que permitem animar e consolidar os investimentos materiais realizados.

Com efeito, os poucos estudos existentes concentram-se na análise do turismo cultural como espaço de preservação do patrimônio (Batista, 2005) e, assim, um item da oferta turística.

\section{RESULTADOS QUANTITATIVOS}

A cronologia dos estudos permite apontar ao longo do tempo, portanto no período de 1987 a 2010, como o interesse no assunto tem se manifestado na esfera acadêmica.

Tabela 1 - Cronologia dos estudos

\begin{tabular}{lcc}
\hline Período & Número de estudos & Percentual em relação ao total da amostra válida \\
\hline 1987 a 1990 & 02 & $2,8 \%$ \\
1991 a 2000 & 16 & $17,3 \%$ \\
2001 a 2010 & 74 & $80,4 \%$ \\
\hline
\end{tabular}

Pode-se observar que houve um crescente interesse na área ao longo do tempo. Embora o primeiro período seja mais curto, conta com estudos produzidos em apenas três anos. Há uma concentração de estudos na última década, indicando que o tema passa a ganhar maior relevância, na medida em que os próprios centros culturais também começam a ter papel de destaque na sociedade. A última década foi a que concentrou o maior número de estudos, com $80,4 \%$ da produção total, e o ano de maior concentração foi o de 2009, com 13 estudos publicados, reforçando a ideia de que o tema passa a ganhar destaque no meio acadêmico muito recentemente, o que pode indicar que análises que levam em conta o "centro cultural" são um tema que apresenta interesse crescente entre pesquisadores acadêmico.

O estado acadêmico permite diagnosticar o nível de complexidade em que o tema foi tratado. 
Tabela 2 - Enquadramento acadêmico

\begin{tabular}{lll}
\hline Nível & Número de estudos & Percentual \\
\hline Dissertações & 79 & $85,9 \%$ \\
Teses & 13 & $14,1 \%$ \\
\hline
\end{tabular}

Os dados apresentam como era de se esperar, uma ampla predominância de estudos em nível de mestrado. Isso pode indicar que o tema pode estar sendo tratado como porta de entrada para pesquisas acadêmicas, pois se notou que as 13 teses de doutorado foram publicadas a partir do ano 2000. Considerando a tendência indicada pelos números aqui apresentados, acredita-se que haverá na próxima década um incremento nas Teses de Doutorado.

Sobre a natureza das IES, discriminaram-se os dados sobre a natureza das instituições onde foram realizados os estudos, se instituições públicas ou privadas.

Tabela 3 - Tipo de IES

\begin{tabular}{lll}
\hline Instituições & Número de estudos & Percentual \\
\hline Privadas & 24 & $26 \%$ \\
Públicas & 68 & $74 \%$ \\
\hline
\end{tabular}

Nota-se que há uma ampla predominância de estudos realizados em instituições públicas. Foram $74 \%$ da amostra válida, contra $26 \%$ de estudos realizados em instituições privadas, refletindo em certa medida a realidade da produção acadêmica no país, na qual há uma predominância de pesquisas sendo realizadas em escolas de caráter público. Os dados indicam também que as instituições privadas poderiam ou deveriam incentivar um maior número de pesquisas sobre o tema, contribuindo para ampliar a oferta de material que estão em sintonia com esta reflexão acadêmica.

Analisou-se também a presença ou não de financiamento de agências de fomento para pesquisas e quais agências.

Tabela 4 - Financiamento das Pesquisas

\begin{tabular}{lll}
\hline Agência de fomento & Número de estudos & Percentual \\
\hline Sem financiamento & 56 & $60,8 \%$ \\
Capes & 21 & $22,8 \%$ \\
Cnpq & 07 & $7,6 \%$ \\
Outros & 08 & $8,6 \%$ \\
\hline
\end{tabular}

Percebe-se que o tema não vem apresentando o esperado interesse das agências financiadoras ou não reuniram as condições necessárias para pleitear auxílio financeiro. Nota-se que aproximadamente $61 \%$ dos estudos foram realizados sem incentivo financeiro e que o restante, aproximadamente $39 \%$ recebeu ajuda de algum fomento à pesquisa. A Capes foi a mais envolvida nos financiamentos para estes estudos, estando presente em $22,8 \%$ das pesquisas que receberam algum auxílio.

A análise da prevalência da expressão "centro cultural" parece ser bastante relevante, pois ela aponta onde, no levantamento do banco de teses, a expressão exata apareceu. Isso pode indicar 
que nível de importância o termo "centro cultural" teve para o estudo, tendo aparecido no título e/ou nas palavras chaves e/ou no resumo. Então seria o estudo mais substantivo aquele em que há maior ocorrência da expressão.

Tabela 5 - Uso da expressão "Centro Cultural”

\begin{tabular}{lcc}
\hline Expressão "centro cultural" & Número de estudos & Percentual em relação ao total \\
\hline Título & 02 & $2,1 \%$ \\
Palavra chave & 00 & $00 \%$ \\
Resumo & 62 & $67,3 \%$ \\
Título e Palavra Chave & 00 & $00 \%$ \\
Título e Resumo & 14 & $15,2 \%$ \\
Título/Palavra Chave e Resumo & 12 & $13,0 \%$ \\
Palavra Chave e Resumo & 02 & $2,1 \%$ \\
\hline
\end{tabular}

Identifica-se uma significativa prevalência da expressão somente no resumo, o que ocorreu em $67,3 \%$ dos estudos apurados. $O$ aparecimento da expressão nos três itens possíveis se deu em $13 \%$ dos estudos. Somando-se os estudos em que expressão aparece em dois ou mais locais chegamos a $30,3 \%$ das pesquisas, ao passo que se somando os estudos em que a expressão aparece em apenas um local, encontram-se 69,4\% dos estudos. Indica-se, portanto, que a prevalência da expressão "centro cultural" não foi tão substantiva como se esperava, o que pode manifestar que os estudos apontados ainda não têm o centro cultural como principal foco de pesquisa, portanto havendo um bom espaço a ser investigado sobre o assunto.

Finalmente, apresentam-se as áreas de conhecimento nas quais foram realizadas as pesquisas.

Tabela 6 - Por área de conhecimento

\begin{tabular}{lcc}
\hline Área do Conhecimento & Número de Estudos & Percentual em relação ao total \\
\hline Administração & 03 & 3,26 \\
\hline
\end{tabular}




\begin{tabular}{llc}
\hline Antropologia & 04 & 4,35 \\
Arquitetura e urbanismo & 10 & 10,87 \\
Artes & 06 & 6,52 \\
Biblioteconomia & 01 & 1,09 \\
Ciência da informação & 04 & 4,35 \\
Ciências da saúde & 01 & 1,09 \\
Ciências sociais aplicadas & 03 & 3,26 \\
Cinema & 01 & 1,09 \\
Comunicação & 09 & 9,78 \\
Direito & 01 & 1,09 \\
Educação & 07 & 7,61 \\
Engenharia & 02 & 2,17 \\
Geologia & 01 & 1,09 \\
História & 06 & 6,52 \\
Interdisciplinar & 03 & 3,26 \\
Letras & 01 & 1,09 \\
Linguística & 02 & 2,17 \\
Literatura comparada & 01 & 1,09 \\
Multidisciplinar & 01 & 1,09 \\
Música & 01 & 1,09 \\
Não mencionado & 10 & 10,87 \\
Psicologia social & 06 & 6,52 \\
Saúde pública & 01 & 1,09 \\
Serviço social & 01 & 1,09 \\
Sociologia & 04 & 4,35 \\
Teatro & 01 & 1,09 \\
Turismo & 01 & 1,09 \\
\hline & &
\end{tabular}

Percebem-se aqui não apenas o grande número de áreas que abrigaram tais estudos, inclusive das ciências exatas de Engenharia e mesmo geologia, bem como a prevalência das áreas, pela ordem de importância, de Arquitetura e Urbanismo, Comunicação, Educação, Artes, Psicologia Social. Relevante, também, é observar que apenas um trabalho originou-se da área de Turismo.

\subsection{Análise segundo as categorias}

Após a análise do cenário geral dos resultados, que teve foco no caráter quantitativo, discutem-se aqui esses resultados, agora sob uma ótica qualitativa. Para tanto, baseado no 
conteúdo dos estudos, estabeleceu-se uma categorização que atendesse aos preceitos metodológicos deste "estado da arte". As categorias e o número de estudos que se enquadram em cada uma delas estão discriminados no quadro abaixo.

Tabela 7 - Distribuição dos estudos segundo as categorias selecionadas

\begin{tabular}{lcc}
\multicolumn{1}{c}{ Categorias } & Número de estudos & Percentual \\
\hline Ação Cultural & 51 & $55,4 \%$ \\
Planejamento da Ação Cultural & 16 & $17,4 \%$ \\
Planejamento do Centro Cultural & 25 & $27,2 \%$ \\
\hline
\end{tabular}

Nota-se uma tendência à prevalência de estudos que estejam ligados à ação cultural, indicando que os interesses de pesquisadores sobre o tema estão ligados preferencialmente à ação produzida nos centros culturais. Nesta categoria encontra-se mais que a metade dos estudos válidos, portanto $55,4 \%$. Num segundo patamar de prevalência se encontrou os estudos ligados ao planejamento de centros culturais, em especial aqueles da área de arquitetura e urbanismo e nesta categoria situam-se $27,2 \%$ dos estudos. Finalmente em menor número aparecem aqueles ligados ao planejamento da ação cultural, totalizando 17,4\%. Tal fato pode indicar que a área de planejamento cultural seja a principal lacuna em pesquisas sobre o centro cultural.

Inicialmente cabe uma descrição sobre cada uma das categorias e nelas algumas citações que ilustram como se deu processo de categorizar os estudos. Abstraíram-se três categorias nesta análise, quais sejam: estudos relacionados à ação cultural, estudos ligados ao planejamento da ação cultural e finalmente aqueles ligados ao planejamento dos centros culturais.

- Ação cultural - incluem-se aqui as dissertações e teses que tratam especificamente da ação dos centros culturais e do significado de sua ação.

Sobre os estudos ligados à ação cultural pretendia-se encontrar aqueles que se alinhassem com o conceito já aqui apontado por Coelho (1997) que define o verbete ação cultural como "processo de criação ou organização das condições necessárias para que as pessoas e grupos inventem seus próprios fins no universo da cultura" (Coelho, 1997, p33). A cultura viva é aquela que resulta dessa ação.

A ação cultural existe a partir do trabalho realizado pelo agente cultural, ou pelo centro cultural visando à democratização do acesso à criação e produção de cultura. Para a autora Luciene Borges Ramos:

Ação cultural pode ser considerada como um processo de intervenção que utiliza o modo operativo da arte, com seu caráter libertário e questionador, para revitalizar laços sociais, promover a criatividade em grupo, criar condições para que ocorram elaborações e práticas culturais. Essas ações se norteiam pelo fomento à criatividade, à pesquisa, è 
ruptura e ao conhecimento sem visar atividades lucrativas. É nessa esfera que se localizam (ou deveriam se localizar) os centros culturais (Ramos, 2008, p.68).

É o caso, por exemplo, de análise da construção da subjetividade de crianças que frequentam o Centro Cultural Cartola (CCC), na Mangueira/RJ, a partir da relação estabelecida entre território, identidade cultural e imagem de si." (Vaz, 2009). Outro exemplo é a tese de Prazeres (1996) que teve como objetivo pesquisar exploratoriamente as iniciativas do Centro Cultural do Banco do Brasil e do Eco Museu do Quarteirão Cultural do Matadouro, na cidade do Rio de Janeiro, e como essas iniciativas culturais podem contribuir, enquanto veículos de evolução cultural".

- Planejamento da ação cultural - incluem-se aqui as dissertações e teses que tratam dos métodos de programação da ação dos centros culturais.

Nesta categoria, buscaram-se os estudos que tratassem do ato de se planejar, organizar, produzir, promover elaborações e práticas culturais. É o caso da pesquisa de Chernicharo (2010) que buscou investigar qual o impacto da promoção e da preservação do legado de Cartola na vida dos jovens atendidos pelo Centro cultural Cartola e da equipe que trabalha nos bastidores para que os projetos sociais se tornem uma realidade.

Outro exemplo é o estudo de Souza (2008) que analisa os critérios de investimento e visa compreender as motivações que sustentam o patrocínio artístico do Banco do Brasil, a partir da análise dos critérios utilizados na seleção dos projetos e na estruturação da programação do centro cultural Banco do Brasil (CCBB) São Paulo, nas áreas de artes cênicas e artes plásticas, nos anos de 2005 e 2006.

- Planejamento de centros culturais - incluem-se aqui as dissertações e teses que tratam especialmente do planejamento físico dos centros culturais.

Dentro desta categoria, pode ser citado como exemplo o estudo de Oliveira (2006) que tem foco específico na acessibilidade de centros culturais visando conhecer as reais necessidades espaciais destas pessoas, a fim de adequar instrumento desenvolvido pelo Ministério Público de Santa Catarina para avaliação das condições de acessibilidade de Centros Culturais e desenvolver princípios projetuais para edifícios destinados à cultura. Outro exemplo nesta categoria é o estudo ligado ao planejamento de centros culturais que investiga a série discursiva que moldou a invenção de suas tradições e as motivações para instalar o centro cultural Banco do Brasil na sua antiga sede no Rio de Janeiro." (Vieira, 2006).

Na categoria Ação Cultural foram classificados 51 estudos, o que já é um obstáculo a ser vencido na tarefa de apresentar linhas comuns nessas pesquisas. Ao analisar as áreas de pesquisa, notou-se que 11 estudos são oriundos das ciências da comunicação, 10 da educação, oito das artes, seis das ciências sociais aplicadas, cinco da história, quatro da psicologia social, dois de 
administração e ainda outros cinco estudos de outras áreas. Considerando a dificuldade e as limitações desta proposta, seguirá abaixo a análise específica do contexto destas pesquisas segmentadas pelas suas áreas de pesquisa.

Nos estudos das ciências da comunicação, Gorczevski (2002) e Ramos (2007), investigam a relação entre cultura e mídia e qual é o papel do centro cultural na sociedade de informação, dando destaque à capacidade destes órgãos em disseminar informação. Os trabalhos de Cabral (1989); Feitosa (1996); Xavier (2009) e Oliveira, (2009) analisam em qual medida as propostas de ação cultural, desenvolvidas em espaços de leitura, bibliotecas e projetos de teatro, contribuem para apropriação da leitura entre o público alvo destes projetos. Ansarah (1988) investiga se o centro cultural está atingindo o objetivo para o qual ele foi criado e se a presença deste centro num determinado local altera a realidade local. A formação da identidade cultural e construção da cidadania são o foco dos estudos de Nogueira (2005) e Dias (2006). Está presente também uma análise da transferência da informação contida numa exposição artística, no trabalho desenvolvido por Carvalho (1998) e finalmente Dantas (2003) analisa a força das mediações socioculturais na reprodução das mensagens ecológicas e como se dá processo de captação destas mensagens pelo público receptor de um evento cultural.

Grande destaque os trabalhos desenvolvidos na área da educação, onde há um conjunto de estudos realizados por Argrigh (1995); Marcondes (1996); Brandão (2004) e Silva (2010) que focam seus esforços em refletir sobre a prática pedagógica desenvolvida em projetos de educação não formal, realizados em centros culturais. Pode-se também notar alguma semelhança nos estudos de Paes (1999); Carvalho (2005) e Silva (2007), cujo foco é a pesquisa sobre os resultados de ações educativas propostas por centros culturais junto às comunidades. No estudo apresentado por Corrêa (2008) é investigada a história da formação de um centro cultural a partir de sua ação num projeto de leitura infantil. Finalmente os estudos de Meira (2002) e Carvalho (2005) analisam a relação entre arte e educação e como a escola se relaciona com o centro cultural.

Nota-se que nos trabalhos desenvolvidos na área de artes, há uma congruência mais clara no foco de pesquisa, em Ruiz (2005); Omar (2002); Maluf (2005); Orloski (2005); Sulzbacher, (2010); Porto (2009); Brilhante (2004) e Silva (2004) em que se pode dizer que a principal reflexão apresentada por estes estudos é o processo de arte-educação que se opera nos centros culturais a partir da visitação de obras artísticas e/ou vinculação a um determinado programa de educação nas linguagens artísticas.

Um primeiro foco de pesquisa encontrado nos estudos das ciências sociais aplicadas é a pesquisa sobre identidade étnica e a possibilidade de convivência e respeito entre etnias diferentes, a partir da ação de um centro cultural, em Mendonça (2005) e Biscoli (2004). Outra fonte de pesquisa são os sentidos produzidos pelos frequentadores de Centros Culturais, a partir da apreciação da obra de arte, em Cerqueira (2006) e Oliveira (2009). No trabalho de Aguiar (1998) houve a intenção de absorver a proposta do centro cultural sobre a relação entre cultura, identidade e política. Há ainda um estudo bastante curioso, de Carvalho (2010), no qual a 
abordagem se dá por uma ótica ficcional, apresentando o contato do autor com o fazer artístico que fora apresentado em um centro cultural da cidade de São Paulo.

Nos estudos apresentados na área de história não há uma aparente congruência. Virino (2009) teve o objetivo de identificar e construir uma análise das práticas como dinâmicas de produção e dos discursos como posturas ideológicas das produtoras de cordel, como temática específica na manifestação cultural da literatura de Cordel. Sbeghen (2001) analisou a história, papel, memória e impacto na sociedade dos museus da cidade de Passo Fundo. Um estudo sobre os caminhos traçados por entidades do movimento negro em Duque de Caxias foi o tema de Pereira (2006).

Outro trabalho desta área apresentado por Nogueira (2005) teve como proposta a análise da obra de Cartola e a montagem de uma exposição no Centro Cultural Cartola. Finalmente Pagani (2001) pesquisou as manifestações nacionalistas na região de colonização italiana, principalmente através da ação dos Centros Culturais Tobias Barreto de Meneses, em Caxias do Sul.

Nos trabalhos na área da psicologia social, encontra-se Vaz (2009) e Ferreira (2009) que estudaram a construção da subjetividade de crianças que frequentam o Centro Cultural Cartola. Lima (2009) estudou as práticas artísticas e terapêuticas que trabalham com a criatividade em jovens que frequentavam o Centro Cultural Cartola. Por fim lorio (2009) investigou um ato psico sócio dramático realizado no Centro Cultural São Paulo buscando identificar qual a sua contribuição para o desenvolvimento de grupos.

$\mathrm{Na}$ área de administração são apenas dois estudos, os desenvolvidos por Reginato (1993) e Castro (2008) ambos investigando os benefícios da ação educativa desenvolvida em centros culturais para a inclusão social.

Finalizando a análise dos estudos que trataram da ação cultural, anda há a intersecção difusa com outra área menos prevalentes, quais sejam: serviço social em que Freitas (2005) que busca entender qual é o trabalho do educador social desenvolvido na ação junto às comunidades carentes de Angola, pelo Centro Cultural Mosaiko. Há um estudo da área do design apresentado por Macêdo (2010) que investiga as contribuições no processo de ensino aprendizagem dos jogos considerados como mediadores do ensino da Arte. Em ciências da saúde há um estudo realizado por Santos (2008) que analisa como a dança poderia integrar o cotidiano de criança e adolescentes do Centro Cultural e de Educação Infantil Menino Jesus. Em arquitetura aparece o estudo de Falcão (2004) que analisa o processo de reconstrução das cidades, em especial as ações que envolvem a utilização de centros culturais como vetores desta transformação urbana. Há finalmente um trabalho da área de ecologia social que explora as iniciativas do Centro Cultural Banco do Brasil como elas podem contribuir enquanto veículos de desenvolvimento cultural.

Nos estudos classificados na categoria de planejamento da ação cultural, houve uma distribuição quase que paritária entre as áreas do conhecimento, não havendo uma que se destacasse. Nos trabalhos vinculados à área das ciências sociais aplicadas, Assis (2007) e Souza (2008) têm no Centro Cultural Banco do Brasil seu objeto de pesquisa e ambos vão discorrer sobre o impacto do investimento e os mecanismos decisórios para o investimento na ação cultural 
proposta por este centro. Também nesta área, está o estudo de Chernicharo (2010) que vai investigar as dificuldades encontradas no setor administrativo do Centro Cultural Cartola em promover a ação cultural a que este centro se propõe.

Outro grupo de estudos desta categoria são os ligados a área da comunicação e ciência da informação, merece destaque o estudo realizado por Cenni (1991) que apresenta algumas tendências que tomaram corpo a partir da década de 80, em instituições culturais da Europa e Estados Unidos. Ele relata que os grandes museus foram se modificando pouco a pouco de instituições sóbrias e silenciosas, verdadeiros guardiões da História e da Arte, para espaços culturais de exposições grandiosas de caráter interativo, verdadeiros sucessos de público. Essas exposições, ditas interativas, tornaram-se a grande moda nos Estados Unidos, chegando a competir com parques da Disneylândia em atratividade de público, provocando nos visitantes estímulos visuais e sonoros, que passam a ser também como uma alternativa de diversão e lazer.

Cenni (1991) destaca, ainda, que qualquer hall de banco é chamado de centro cultural e uma antessala é considerada galeria. Além disso, observa-se uma confusão teórica entre cultura e lazer, ou com turismo, ou ainda com educação. Nesse cenário, o planejamento da ação cultural está cada vez mais ligado a planejamentos mercadológicos que se tornam determinantes. Há cada vez mais uma preocupação com a frequência de público e com o consumo de bens culturais do que com os conteúdos propostos. Além disso, banaliza-se a noção de ação cultural, na medida em se a considera como a simples presença de algum elemento cultural nesta ação.

Cenni (1991) apresenta ainda um quadro comparativo com as características organizacionais e de planejamento de três importantes centros culturais da cidade de São Paulo, o Centro Cultural São Paulo, o Museu Lasar Segall e o SESC Pompeia. Ele finaliza indagando qual é o papel central dos centros culturais.

Destaca-se também o trabalho de Assis, 2010 que analisa o papel de centros culturais na cidade de Belo Horizonte, apresentando como estes funcionam e se estruturam na construção de uma rede voltada para o acesso à cultura na capital mineira.

Os trabalhos de Ferreira (2000); Mussel (2004) e Claudio (2007) estão voltados à compreensão do discurso ideológico, da formação da identidade e das tentativas de implantação de políticas culturais realizadas por centros culturais.

Na área da administração encontram-se nesta categoria os estudos de Lemos, (1994); Carneiro (2008); Mantoan (2010), todos preocupados em analisar o processo decisório, modelo de gestão e o papel da liderança no gerenciamento das organizações, enfatizando os modelos existentes para atender a demanda imposta de promoção da ação cultural.

$\mathrm{Na}$ área de História, encontra-se o estudo de Pereira (2005), que vai analisar como a ação dos Centros Culturais influenciou, ao longo das épocas, as manifestações culturais e a própria noção de cultura.

$\mathrm{Na}$ área de Educação, destacam-se os estudos ligados à educação. Bandeira (2010) investigou como o centro cultural, por meio de sua ação, influenciou na formação de jovens em situação de risco, na periferia da cidade de Fortaleza. Já o estudo de Oliveira (1989) vai mostrar 
por meio de um relato de experiência de como um projeto de arte-educação pode servir de estratégia educativa para o público em geral. Também na área da educação, Arantes e Silva (2010) visam apresentar um perfil do público atendido em centro cultural da juventude, mostrando como este público utiliza e de que modo este equipamento pode auxiliar na consolidação de novas ações empreendidas por estes jovens.

Finalmente há um estudo realizado por Mansur (2003) que se trata de um projeto isolado, portanto não pertencente a nenhuma área especifica. Este estudo mostra como as leis de incentivo influenciam no estabelecimento de uma política cultural, neste caso no estado de Minas Gerais.

Ramos (2008) descreve algumas características que devem ser levadas em consideração quando se planeja um centro cultural. Para ela, esses espaços constituem espaços da comunidade: o público deve se sentir convidado a entrar e participar, deve haver estímulo para que os frequentadores expressem seus sentimentos, participando ativamente como protagonistas se apropriando dos espaços. O centro cultural deve permitir a circulação de ideias, sons, imagens, pensamentos que possibilitem ao frequentador a exploração de sua própria subjetividade e de se encontrarem com suas emoções pessoais.

Aqui, a área de maior prevalência é a de arquitetura e urbanismo, com 13 estudos. Nesta área, Silva (2000); Telles (2002); Smith (2006) estudam e analisam criticamente o conceito dos projetos arquitetônicos de Centros Culturais.

Outros autores como Ribeiro (2000); Pereira (2007); Martins (2006); Gomes (2009) vão estudar principalmente as implicações arquitetônicas envolvidas num processo de restauro e ou adaptações necessárias à implantação de um centro cultural. Semelhante a este enfoque está o estudo de Oliveira (2006), que analisa as implicações de acessibilidade que devem ser considerados num projeto arquitetônico que irá abrigar um centro cultural.

Já Castro (2007) e Carotenuto (2009) analisam as tecnologias de construção empregadas na execução de uma obra destinada a receber um centro cultural. Finalmente dentro da área de arquitetura e urbanismo ainda há que se considerarem os estudos de Dudeque (2009), Paula (2010) e Barbosa (2006) que analisam a relação entre a arquitetura destes centros com arquitetura local do espaço urbano ao qual eles estão inseridos.

$\mathrm{Na}$ área de comunicação encontram-se os estudos realizados por Akamine (1999) e Costa Júnior (2006) que buscam avaliar a construção da identidade destes centros junto à população local e como se dá esse processo a partir da avaliação de processos de comunicação entre o centro cultural e a população.

Outra área presente e a da educação, dos estudos de Araújo, (2010) e Rosa (2008). Nestes estudos busca- se identificar como a ação educativa influencia na constituição conceitual de um centro cultural.

Há espaço também para uma produção acadêmica oriunda das ciências sociais aplicadas, e neste âmbito, encontram-se os estudos de Cunha (2003), Pozzer (2007), Santos (2010), Vieira (2006), Vendramini (2006), Vieira (2004) e Pedrosa (2009). Nestes estudos há um variado enfoque, 
mas em linhas gerais buscam refletir sobre a memória e o imaginário, sobre a inserção de edificações culturais no espaço urbano, sobre as alterações ambientais e culturais provocadas a partir da implantação de um centro cultural e sobre o enobrecimento urbano (gentrificação) consequente a esta implantação.

Finalmente apenas o estudo produzido por Mello e Silva (1995) está relacionado à área de administração e busca analisar as características administrativas de instituições denominadas de centro cultural.

\section{CONSIDERAÇÕES FINAIS}

O ex-ministro da Cultura Sérgio Paulo Rouannet perguntou-se em diferentes oportunidades: "se tudo é cultura, o que é mesmo cultura?". Nessa frase jocosa, ele ao mesmo tempo distinguiu os sentidos descritivo e formativo, como também se mostrou afinado com o sentido formativo de cultura, o que vem ocorrendo, como se comentou aqui em várias oportunidades, desde o primeiro nome (Andre Malraux) a assumir um ministério, no caso na França, com essa denominação.

Nesta mesma linha de raciocínio, pode-se dizer que os centros culturais são espaços de difusão de uma ação cultural propositiva, vinculada ao desenvolvimento do cidadão. Atualmente, nota-se um grande desenvolvimento do setor artístico cultural, que resulta de um processo de profissionalização e crescente volume de atividades neste setor. As leis de incentivo estão disseminadas e cada vez mais acessíveis aos produtores de cultura, transformando-se numa ferramenta para a difusão cultural. Logo, os centros culturais são representantes deste setor, sendo o local para as práticas relacionadas à cultura. Por mais polissêmico que se apresente o conceito de cultura, parece claro que o sentido formativo está ligado ao papel dos centros culturais na sociedade contemporânea.

A título de resultados da revisão da produção bibliográfica, podem ser apresentadas as seguintes tendências:

O referencial teórico adotado mostra que a designação centro cultural pode englobar uma multiplicidade de equipamentos urbanos, incluindo museus, bibliotecas, que cada vez mais assumem a vocação, não apenas de conservadores, mas também de produtores de cultura, com oficinas, cursos, etc.

Pode-se identificar também que essa noção ganha ainda mais opacidade, ao se considerar que as iniciativas se multiplicam tanto nos setores público e privado sem fins lucrativos (ONGs) como também no setor privado, sobretudo bancos.

Observou-se que alguns autores, como Teixeira Coelho, Milanesi e Ramos, enfatizam que os centros culturais devem investir numa produção de cultura da inquietação e da inovação. Portanto devem ir além de um espaço de lazer e fruição, fugindo do mero entretenimento, partindo para a promoção de uma ação cultural que possibilite aos usuários apreendam a 
dominem os rudimentos das artes, a partir do acesso democrático de bens simbólicos vivenciando experiências coletivas.

Destacam-se, nos centros culturais, três campos de atuação com a cultura: a criação, que em geral acontece por meio de cursos e oficinas que visam à formação artística e à educação estética. O segundo campo é o da circulação, que ocorre através de uma política de atividades e eventos, com vistas à formação de público. E, por último, o campo da preservação do patrimônio cultural intangível, baseado na relevância da manutenção da memória cultural de uma coletividade.

Em que pesem as limitações metodológicas do presente estudo e do seu caráter preliminar, podem-se apontar alguns resultados relevantes.

- Nota-se uma crescente produção acadêmica sobre o tema - daí a necessidade de maior aprofundamento.

Como era de se esperar, há predominância de dissertações em relação às teses, o que indica que o tema cada vez mais adquire o perfil dos temas já consagrados, com as dissertações sendo porta de entrada para as reflexões científicas.

- Notam-se, ainda, nos estudos levantados, três vieses redutores. Nos dois primeiros, em especial, os referenciais teóricos de turismo e lazer não encontram eco.

Curiosamente, como já fartamente ilustrado aqui, embora os centros culturais sejam atrativos turísticos de grande importância, constituindo referências (poder-se-ia mesmo dizer grifes) de grandes metrópoles e exista já um crescente número de estudos que relacionam cultura e turismo, não há nenhum estudo que relacione estas duas áreas com os centros culturais.

Isto ocorre, quem sabe, devido ao fato de que os temas da cultura e do turismo tratados conjuntamente ainda carecem de consolidação. Ou, visto de outra forma, mostra o imenso campo de estudo que se abre. Minimiza-se esta referência ao observar que alguns autores importantes como Teixeira Coelho, Milanesi e Ramos, citados logo acima, esquecem a dimensão de lazer associando este a simples entretenimento, deixando de lado a vertente teórica do lazer sócioeducativo e do turismo cultural. Afinal, visitar, participar de oficinas, de estudos culturais nesses centros, são atividades de tempo livre, da qual os indivíduos participam espontaneamente e não como currículo escolar, mas ao mesmo tempo visando ao desenvolvimento pessoal, não havendo, pois, como se justificar tal viés. Esta observação deve ser minimizada pela hipótese de que o turismo e o lazer encontrem-se estudados em áreas como administração e, sobretudo comunicação.

- Em terceiro lugar, nota-se que os estudos (e o próprio panorama atual das iniciativas de criação desses equipamentos urbanos) privilegiam os campos intelectual e artístico da ação cultural, esquecendo o campo da cultura física, do lazer e, como já exposto, do turismo.

As caminhadas, a ginástica e o esporte, as iniciativas de turismo social que, não raro, fazem parte da ação de alguns centros culturais, não seriam também campos a serem tratados na intersecção dos conceitos de cultura, ação cultural, turismo e lazer? Deve-se esquecer de que tais 
atividades devem ser tratadas como cultura e como produtos de uma civilização? Afinal, o turismo é, em si, cultura ou, ao menos, uma atividade cultural em que predomina o desejo de mudança de paisagem, de ritmo e de estilo de vida. Nesse sentido, é o espaço por excelência da alteridade, na forma expressa por Michel Serrès (1997), do tiers-instruit (terceiro instruído) como produto da interação de dois instruídos (o turista e o residente). Essa filosofia mestiça pode constituir um dos suportes para o entendimento da importância do turismo para a cultura.

Inversamente, pois, cabe aos estudiosos do turismo delimitar melhor os significados da noção de cultura embutida em expressões como turismo cultural, turismo pedagógico, etc.: as demais formas de turismo também não são culturais e pedagógicas? Em toda mudança de paisagem física e humana, de ritmo e de estilo de vida, não se aprende algo? O que se sabe sobre as mudanças de perspectiva de vida, de mentalidade, de conhecimento, etc. que acontecem e se acontecem durante a viagem?

Aliás, os estudos sobre cultura, mesmo cientes da amplitude do conceito na antropologia, insistem em considerá-la apenas nos âmbitos intelectual e artístico, permitindo-se mesmo que se pergunte se o próprio surgimento dos centros culturais não está associado a uma noção aristocrática e de distinção social (BOURDIEU, 2007), reproduzindo o preconceito que privilegia o espírito, considerando-o superior ao corpo!

Neste sentido, ao se analisarem os estudos sobre centros culturais, nota-se que as questões trazidas pelos pesquisadores abordam, no seu espectro geral, a gestão dos espaços culturais, repertório cultural, acesso e linguagens, formação de quadros, sustentabilidade e modelos administrativo-financeiros. São estudos que provêm da filosofia, da teoria do imaginário, da arquitetura e urbanismo, da psicanálise, dos artistas e criadores, das novas formas de fruição. Portanto, surgem de diferentes áreas que colaboram para resignificar a noção de centro cultural.

Reconheceu-se nos estudos sobre esses espaços sua vocação para a dimensão cultural da vida simbólica, pois nele mora o espaço para a imaginação, o sonho e a criatividade. São dimensões da vida humana ligada ao campo da subjetividade, do desejo e do imaginário. Logo, acreditar que o homem é capaz de imaginar, sonhar, criar, produzir imagens, manifestando sua passagem pela vida é o que dá estofo para a constituição dos centros culturais. Nesse sentido, é possível admitir que a ação cultural organizada e regularizada desenvolvida em centros culturais ao longo de todo território nacional, produz efeitos nas comunidades em que atua e, certamente, nos turistas. Pois, ao oferecer produtos culturais, possibilita a distribuição mais democrática de objetos e riquezas imateriais.

\section{REFERÊNCIAS}

Batista, Cláudio M. (2005) Memória e identidade: aspectos relevantes para o desenvolvimento do turismo cultural. Caderno Virtual de Turismo, v. 5, n. 3.

Bourdieu, Pierre. (2007). A distinção: crítica social do julgamento. São Paulo: Edusp; Porto Alegre, RS: Zouk.

Cunha, Newton. (2010) Cultura e Ação Cultural. São Paulo: Edições SESCSP. 
Durand, José Carlos. (2001) Cultura como objeto de política pública. Revista São Paulo em Perspectiva, 15 (2).

Elias, Nobert. (1990). Sobre o processo da civilização, investigações sociogenéticas e psicogenéticas. Rio de Janeiro: Jorge Zahar.

Ferreira, Norma (2002). As pesquisas denominadas "Estado da Arte". Educação \& Sociedade. 23(79), agosto.

Garcia, Daniela; BAHL, Miguel (2011). As contribuições da Nova Geografia Cultural na atividade turística. Revista Brasileira de Pesquisa em Turismo. 5 (1), pp.23-44,

Gonçalves, Sérgio C. Cultura e Sociedade de Consumo: um olhar em retrospecto. InREVISTA, ano 3, no 5, 2008

Jaeger, Werner. (1989). Paidéia: a formação do homem grego. São Paulo: Editora Martins Fontes.

Moraes, Roque (2003). Uma tempestade de luz: a compreensão possibilitada pela análise textual discursiva. Ciência \& Educação, v. 9, n. 2, p. 191-211

Ramos, Luciene Borges.(2008). Centros de Cultura Espaços de Informação - Um estudo sobre a ação do Galpão Cine Horto, Belo Horizonte: Argumentum.

Santos, José Luiz dos. (1996). O que é Cultura. São Paulo: Brasiliense.

Serrès, Michel (1997). O terceiro instruído. Lisboa: Instituto Piaget, 1997.

Teixeira Coelho, José R. (1986).Usos da cultura: políticas de ação cultural. Rio de Janeiro: Paz e Terra. (1997).Dicionário Crítico de Política Cultural. São Paulo: Ed. Iluminuras.

Nota: como ocorre em análises de produção bibliográfica, os autores de dissertações e teses (item Análise segundo as categorias) não constam destas referências. Remete-se, contudo, os interessados nos dados completos de autor e obra ao site http://portal.anhembi.br/wpcontent/uploads/dissertacoes mestrado/dissertacao mario-fernandes-da-silva.pdf.

Artigo recebido em: 06/06/2013. Artigo aprovado em: 26/03/2014. 